\title{
Identification of Technogenic Disturbances of Urban Ecosystems Using the Methods of Bioindication and Biotesting
}

\author{
Oksana Anatolievna Pospelova, Yulia Alexandrovna Mandra, \\ Elena Evgenievna Stepanenko, Svetlana Vasilievna Okrut \\ and Tamara Georgievna Zelenskaya
}

Stavropol State Agrarian University, 12, Zootechnicheskiy Line, Stavropol, Russia 355017

DOI: http://dx.doi.org/10.13005/bbra/1897

(Received: 25 September 2015; accepted: 06 November 2015)

The research was aimed at identifying disturbances of urban ecosystems components using the methods of bioindication and biotesting. Soil phytotoxicity, fluctuating asymmetry of Betula pendula, complex of traits in Pinus sylvestris in functional areas of the city located in various geomorphological conditions were studied. The integral coefficient of preservation has been calculated for the studied territories. The greatest degree of ecosystems degradation caused by anthropogenic loads was identified in the major industrial area and in residential neighborhoods located on the slopes of the river valley, with relatively low degree of vehicle load and complete absence of industrial enterprises. This type of landscapes is downslope. Such landscapes are characterized by inflow of chemical elements with lateral solid and liquid runoff. Elements are removed not only with the seepage water in vertical water exchange, but also along the slope with surface and groundwater, circulating water, falling and slipping down soil and rocks. The research has identified a considerable increase in soils phytotoxicity, changes in the fluctuating asymmetry on the slopes of river valleys. The obtained data indicate the fact that the manifestation of non-directional asymmetry of leaves may depend not only on the atmospheric transport of pollutants, but also on their migration with surface runoff, which therefore requires additional studies, including chemical analysis of soils.

Key words: Phytotoxicity, fluctuating asymmetry, ecosystem, industrial zone, residential area, landscape.

Urban systems and their components are difficult to study, because they are systems formed on natural landscapes, which subsequently undergo considerable deformation. As a result of these processes, on the territory of the city one can find both natural ecosystems, and considerably transformed ones, or those created artificially. The ecological state of urban landscape

* To whom all correspondence should be addressed. depends on many factors, which are not always possible to take into account. Unfortunately, there are still no unified requirements, which would make it possible to assess how urban ecosystems cope with the anthropogenic impact. Most studies are focused on pollution of natural environment with heavy metal, and data about their content and distribution are ascertained (Vorobyov, 2005; Frost, 2013). The problem is that the maximum allowable concentrations of contaminants are an integrated index of chemical substances that are harmless to humans only. Furthermore, soil is a depositing environment that is capable to accumulate for long time and retain a variety of pollutants that could 
cause manifestations of toxic effect on living organisms (Alekseev, 1987). Accumulation of pollutants may not depend on properties of the soil itself (Kapusta \& Lukasz, 2015), and may closely correlate with its properties (Degtyareva, 2003). Literature sources present evidence of the fact that higher plants are effective as indicators of both soil contamination with heavy metals (Yoon, Y., Lee, W. \& An, Y. 2015) and atmospheric air contamination (Yesyakova, Stepen, 2008). In connection with the foregoing, one of the promising areas of environmental studies is biomonitoring, which makes it possible to identify disturbances in ecosystems at an early stage. New informative test-systems are also being searched for at the cellular level (Shimanskaya et al., 2014).

This work was performed within the framework of annual monitoring of various functional zones of the Stavropol city performed by the Department of Ecology and Landscape Construction of the Stavropol State Agrarian University. The main purpose of the research is to create an informative test system that would allow to identify abnormalities in various landscapes of the city. The objectives of the research are the following: studying soils phytotoxicity, the fluctuating asymmetry of Betula pendula in urban landscapes (Tkachenko, 2012; Pospelova, Tkachenko, 2013), as well as complex of traits in Pinus sylvestris, in order to identify the dependence of these indicators not only on the degree of anthropogenic loading of functional zones in the city, but on the geomorphological conditions that influence migration of pollutants in the air and water flows as well.

Uneven distribution of pollutants in the environment can cause both stimulatory and inhibitory effects, resulting in various reactions to them of various test organisms. In this regard, we attempted to generalize the results of biomonitoring by calculating the integral coefficient of ecosystems preservation.

The obtained data may be used for predicting the quality of urban environment in planning environmental protection measures, implementation of environmental regulation, environmental assessment and environmental monitoring.

\section{METHODS}

\section{The principles for determining the quadrats for the research}

In analyzing the anthropogenic impact on the soil cover of the city, the natural landscape factors (watersheds of rivers, sloping landscapes) and the factor of functional zoning of the city (industrial, residential, and forest zones) were taken into account.

\section{As a result, we selected and surveyed}

a) forest zones;

b) industrial areas of the city located in watersheds of small rivers (the NorthWestern industrial area; the South-West industrial area; the Eastern industrial area).

For residential areas, the following types were specified:

a) - plateau-residential (multi-storey) area located in the southwestern part of the city with dominating vehicle load;

b) $\quad \mathrm{I}_{\mathrm{a}}$ - plateau-residential (multi-storey) area located in the northwestern part of the city with dominating vehicle load;

c) II - watershed-residential (mixed) zone that occupies the center of the city in the watersheds of the Tashla and Mamayka rivers. Within the area, both low-rise buildings with many secondary roads, often with damaged coating or no coating at all, and high-rise buildings may be identified;

d) III - slope-residential (low rise) area with predominant vehicles load located on the slopes of valleys of the Tashla (III) and the Mamayka (III a) rivers.

\section{Methods of assessing soils phytotoxicity}

Soil phytotoxicity was studied once. To do so, a sample of soil was taken in a specified point using the envelope method from the depth of 0 to $20 \mathrm{~cm}$. The soil collected in the recreational areas of the city was taken for control. The control areas that the samples of soil were taken from are located no closer than 150 meters from the nearest roads (this distance is considered to exclude the air-borne ingress of heavy metals into the soil from the main source of pollution - vehicles). 
For the purpose of biotesting soil, joint samples were taken from the quadrats, consisting of 5 samples from the area of $5 \times 5$ meters placed in an envelope pattern. Samples were taken at each point in the area equal to $300 \mathrm{~m}^{2}$.

The aqueous extracts of soils for biotesting were prepared as follows: one part of air-dry soil sieved trough a $1 \mathrm{~mm}$ mesh sieve was shaken with four parts of distilled water for 15 minutes. The obtained mixture was allowed to settle for 24 hours. Then the soil suspension was shaken once more and filtered through the entire soil thickness on a folded paper filter. The obtained extract was used for biotesting.

Phytotoxicity was determined for all samples of soil according to the "Method of Performing Morpho-Physiological Assessment of Winter Wheat Seedlings" (2005). The method is based on germinating winter wheat seedlings in rolls of filter paper and polyethylene film and taking into account the morpho-physiological characteristics of the seedlings (length of the stem, the number of embryonic roots, defects in development, and the biomass).

In order to determine the phytotoxic effect more precisely, the seeds were germinated in distilled water (control).

The phytotoxic effect was determined according to the formula:

$$
\text { Phe } \frac{M c \quad M h}{M c} .100 \text {, }
$$

where

$P_{h e}$ is the phytotoxic effect;

$M_{c}$ is the biomass of the plant in the control;

$M_{h}$ is the biomass of the plants in the test sample.

The phytotoxic effect (phytotoxicity) was determined according to the following scale:

0 - 10 - no phytotoxic effect;

10 - 30 - weak phytotoxic effect;

30 - 50 - medium phytotoxic effect;

$>50$ - unacceptable phytotoxicity.

According to the methodology of using the criteria for assessing ecological situation of

Table 1. The scale for assessing deviations in the condition of Betula pendula from the conditional standard (Zakharov et al., 2000)

\begin{tabular}{|c|c|c|}
\hline Score & $\begin{array}{l}\text { The value of the indicator of development } \\
\text { stability (the FA indicator) }\end{array}$ & $\begin{array}{l}\text { Characteristics of the environmental } \\
\text { condition of the territory }\end{array}$ \\
\hline 1 & $<0.040$ & Conditionally clean \\
\hline 2 & $0.040-0.044$ & Disturbed \\
\hline 3 & $0.045-0.049$ & Considerably disturbed \\
\hline 4 & $0.050-0.054$ & Adverse \\
\hline 5 & $>0.054$ & Extremely adverse \\
\hline
\end{tabular}

Table 2. The state of the ecosystems by the integral coefficient of preservation

\begin{tabular}{ll}
\hline ICP value & The degree of ecosystems degradation \\
\hline $100-80 \%$ & Regional background (almost undisturbed) \\
$80-20 \%$ & Simplified phytocenosis structure \\
Below 20\% & Anthropogenic desert \\
\hline
\end{tabular}

Table 3. Environmental assessment of soil condition in the industrial districts of Stavropol.

\begin{tabular}{lcc}
\hline Region & Multiplicity compared to the background & Environmental condition \\
\hline $\begin{array}{l}\text { Forest areas } \\
\text { The North-Western industrial area }\end{array}$ & - & - \\
The South-Western industrial area & 1.3 & Environmental disaster \\
The Eastern industrial area & 1.6 & Relatively satisfactory \\
\end{tabular}


territories for revealing zones of emergency ecological situation and zones of ecological disasters, as approved by the Ministry of Natural Resources on November 30, 1992, the comprehensive indicator of soil contamination is phytotoxicity, i.e., contaminated soil ability to inhibit germination of seeds, growth and development of higher plants.
According to this method, soil phytotoxicity (reducing the number of seedlings) is defined as the ratio to the background:

- below 1.1 - a relatively satisfactory situation; - 1.3 to 2.0 - emergency environmental situation; and

- over 2.0 - environmental disaster.

Table 4. Environmental assessment of soils in residential areas in Stavropol

\begin{tabular}{|c|c|c|c|}
\hline Region & $\begin{array}{l}\text { Number of } \\
\text { shoots, pcs. }\end{array}$ & $\begin{array}{l}\text { Multiplicity compared } \\
\text { to the background }\end{array}$ & Environmental condition \\
\hline Forest areas & 8 & - & - \\
\hline Residential high-rise $\left(\mathrm{I}, \mathrm{I}_{\mathrm{a}}\right.$ ) area & 6.8 & - & $\begin{array}{l}\text { Satisfactory environmental } \\
\text { situation }\end{array}$ \\
\hline Mixed residential (II) area & 11.6 & 1.5 & $\begin{array}{l}\text { Emergency environmental } \\
\text { situation; }\end{array}$ \\
\hline \multicolumn{4}{|l|}{$\begin{array}{l}\text { Low-rise residential area } \\
\text { (the slope of the valley of the }\end{array}$} \\
\hline Tashla river) (III) & 8.0 & - & $\begin{array}{l}\text { Satisfactory environmental } \\
\text { situation }\end{array}$ \\
\hline $\begin{array}{l}\text { Low-rise residential area (the slope } \\
\text { valley of the Mamayka River) (III }{ }_{\mathrm{a}} \text { ) }\end{array}$ & $\begin{array}{l}\text { f the } \\
18.7\end{array}$ & 2.3 & Environmental disaster \\
\hline
\end{tabular}

Table 5. Comparative assessment of the coefficient of fluctuating asymmetry in functional areas of Stavropol

\begin{tabular}{lcc}
\hline Functional area & $\begin{array}{c}\text { The value of the indicator } \\
\text { of development stability } \\
\text { (the FA indicator) }\end{array}$ & $\begin{array}{l}\text { Characteristics of the environ } \\
\text { mental condition of the territory }\end{array}$ \\
\hline Forest area (average) & 0.0418 & Disturbed \\
The North-Western industrial area & 0.045 & 0.049 \\
The South-Western industrial area & 0.049 & $\begin{array}{l}\text { Considerably disturbed } \\
\text { Considerably disturbed }\end{array}$ \\
$\begin{array}{l}\text { The Eastern industrial area } \\
\text { Residential high-rise (I, I) area }\end{array}$ & 0.044 & $\begin{array}{l}\text { Considerably disturbed } \\
\text { Mixed residential (II) area }\end{array}$ \\
$\begin{array}{l}\text { Low-rise residential area (the slope of } \\
\text { the valley of the Tashla river) (III) }\end{array}$ & 0.048 & $\begin{array}{l}\text { Considerably disturbed } \\
\text { Low-rise residential area(the slope of the } \\
\text { valley of the Mamayka river) (III) }\end{array}$ \\
\end{tabular}

Table 6. The correlation matrix of morphometric indicators in Pinus sylvestris

\begin{tabular}{lcccc}
\hline \multirow{2}{*}{ Indicatorof needles } & \multicolumn{4}{c}{ The correlation coefficient (r) } \\
\cline { 2 - 5 } & width, mm & length, mm & weight, g & density, pcs. \\
\hline length, mm & -0.97 & - & 0.99 & -0.80 \\
width, mm & - & -0.97 & -0.97 & -0.80 \\
density, pcs. & -0.80 & -0.80 & -0.79 & - \\
weight, g & -0.97 & 0.99 & - & -0.79 \\
\hline
\end{tabular}


Methods of assessing the fluctuating asymmetry of Betula pendula

The fluctuating asymmetry was analyzed and assessed for Betula pendula, which is most convenient for bioindicative purposes. The universality of this type is noted in a number of works of various authors (Zakharov, Clarke, 1993; Zakharov et al, 2000; Konstantinov, E.L., 2001; Korosov, 2007). The choice of this bioindicator was also caused by its prevalence throughout the city.

For the purpose of obtaining complete information, the samples were taken from experimental plots, as defined above.

To obtain statistically reliable data, 50 leaves were collected from each test site from five conventionally even-aged trees of Betula pendula. The leaves were collected $1.5-2 \mathrm{~m}$ from the ground surface. Each leave was measured on the left and on the right by five (main) parameters:

a) the width of the halves of the leaf;

b) the length of the second order nerve that is the second from the base of the leaf;

c) the distance between the bases of the first and second nerves of the second order;

d) the distance between the ends of these nerves;

e) the angle between the main vein and the second from bottom nerve of the second order.

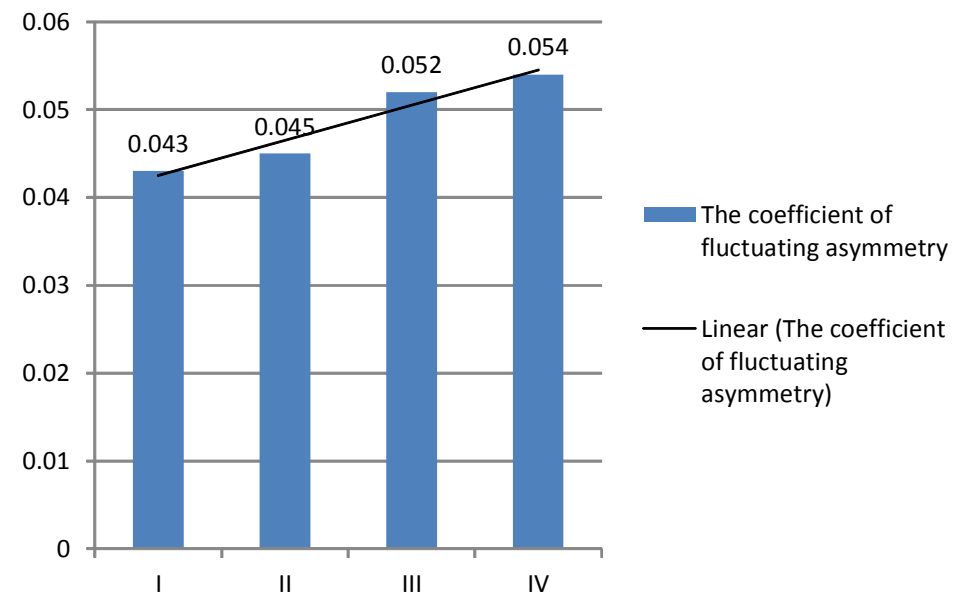

I-eluvial landscape; II-transeluvial landscape; III-transeluvial-accumulative landscape; IV- trans-super-aqual landscape

Fig. 1. Changes in the Coefficient of Fluctuating Asymmetry along the highway located in adjacent landscapes

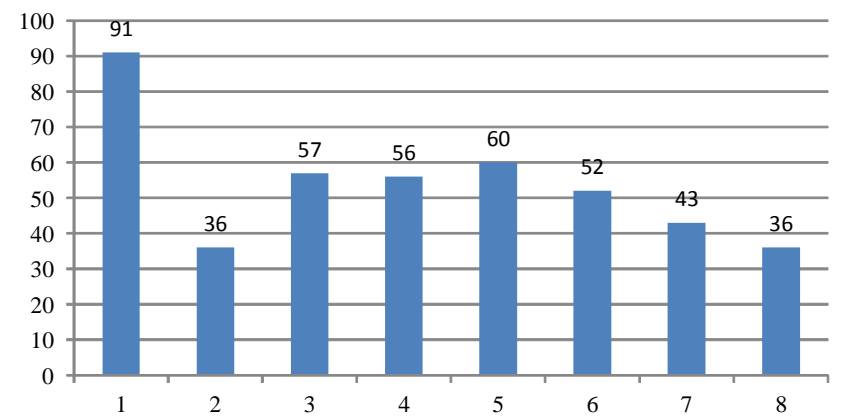

1 - the forest area (average); 2 - the North-Western industrial area; 3 - the South-Western industrial zone; 4 the Eastern industrial area; 5 - the residential multi-storey (I, I $\mathrm{a}_{\mathrm{a}}$ area; 6 - the mixed residential (II) area; 7 - the residential low-rise area (the slope of the valley of the Tashla River) (III); 8 - the residential low-rise area (the slope of the valley of the Mamayka river) (III $\left.{ }_{\mathrm{a}}\right)$

Fig. 2. The Integral Coefficient of Preservation of ecosystems in various functional areas and landscape of Stavropo 
These measurements were performed with the use of a slide caliper, a ruler and a protractor.

For assessing the degree of violation in the stability of silver birch development, and, consequently, for assessing the disturbances in the ecosystem, a scale (table 1) was used, where the first point corresponds to the conditional norm, and the fifth indicates very adverse state of the environment.

\section{Methods of assessing the environment by the} complex of traits in Pinus sylvestris

The state of environment by the complex of traits in Pinus sylvestris was assessed using the following method: three plants of Pinus sylvestris were selected in the quadrats. They had the age of $10-15$ years, and were not affected by chafer, pine noctuid, or sawfly. The total of 225 Pinus sylvestris trees was studied.

The life span of Pinus sylvestris needles was determined by visual inspection, after which the index of needles life expectancy (Q) was calculated:

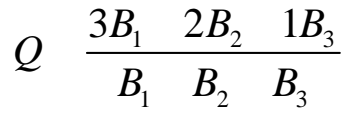

where $B_{1}, B_{2}, B_{3}$ are the numbers of inspected trees with specified life span of needles.

The life span of needles is directly proportional to index $\mathrm{Q}$.

On shoots from the previous year with the length of $10 \mathrm{~cm}$, the number of needles of the age was counted. When the length of the shoot was less than $10 \mathrm{~cm}$, calculation was made along the existing length, and then mathematically translated into $10 \mathrm{~cm}$. Since this indicator is directly a relevant indicator of air pollution, the shoots facing the anthropogenic load (highways, industrial enterprises, etc.) were inspected.

Next, length and width of 250 pairs of needles of the second year of life were measured. Each needle was examined for symptoms of chlorosis and necrosis of the tips and the whole surface, and their number and quality as well. In accordance with the established scales (Denisova, 1999; Fedorova, Nikolskaya, 2001), the class of damage (CD) and the class of drying (CD) were determined for needles, which made it possible to assess the degree of the anthropogenic impact on the territory.
This method was successfully tested is performing biomonitoring in Kislovodsk (Mandra, 2010).

Calculation of the degree of ecosystem degradation by the method of integral preservation factor

For comprehensive numerical evaluation of community degradation under the influence of various factors, the method of integral factor in ecosystems preservation was applied (Stepanov, 1988, 1991). The method consists in calculating the arithmetic mean of all measured values for each indicator (morphometric indicators of pine needles, the size of the birch leaf blade, the degree of asymmetry, soil phytotoxicity) after preliminary division by the corresponding value for the reference point, which is taken as $100 \%$.

Thus, generalization of the result is achieved, which may be represented by a single value, which was called the integral coefficient of preservation (ICP):

$$
\operatorname{ICP} \frac{1}{n}_{n 1}^{i} \frac{A_{i j}}{A_{i k}}
$$

where

$A_{i j}$ is the value of the $\mathrm{j}^{\text {th }}$ indicator,

$A_{i k}$ is the control value of the same $j^{\text {th }}$ indicator, and $i$ is the number of quadrats.

Assessing the ecological state of the environment using the methods of bioindication and biotesting

Defining soils phytotoxicity using the method of biotesting

Soils phytotoxicity in the industrial areas of the city

Phytotoxicity of the soil cover in the city of Stavropol changed in wide enough limits: the fluctuations ranged between $13.8 \%$ - the Russian Forest Dacha natural boundary (weak phytotoxic effect) and $57.7 \%$ (unacceptable phytotoxicity) intersection of the major highways. The average phytotoxicity in the city is $36.5 \%$. For the forest areas, it was $26.8 \%$, for industrial areas $-40.8 \%$, and for residential areas - $34.3 \%$.

Phytotoxicity of soils in the forest zone of Stavropol changed in the range between $16.44 \%$ and $34.7 \%$. In forest areas, soil phytotoxicity is close to the transition values between the mild and the moderate ones. The highest values of phytotoxicity were observed in the areas adjacent 
to highways - $34.7 \%$, the lowest - in the central areas of forests that are most remote from highways and industrial enterprises - $16.4 \%$.

The highest phytotoxicity of soils is characteristic for the north-western industrial zone - 49.8\%. A trend was observed to reducing 14.7 times the number of seedlings with stem length $>10 \mathrm{~cm}$, as compared to the reference samples. Decreased number of seedlings in this group leads to increasing the share of seedlings with stem length $5-10 \mathrm{~cm}$ and $<5 \mathrm{~cm}$, respectively.

Soil phytotoxicity in the whole of the South-West industrial zone was $31 \%$, which corresponds to medium phytotoxicity, distributing in the range between $30 \%$ and $32 \%$.

Compared to the reference samples, a considerable redistribution of seedlings in groups was observed. Decreased number of seedlings with stem length over $10 \mathrm{~cm}$ decreased on the average by $10 \%$. The number of seedlings with stem length of 5 to $10 \mathrm{~cm}$ in the experimental plots in the studied area increased 3.6 times. Reduced seed germination was accompanied by reduced biomass of seedlings. The analysis of the average length of the surviving seedlings shows that the phytotoxic effect is manifested not only in inhibition. We can see that the predicted chain of events: «absence of phytotoxicity - increased germinating capacity - increased length of seedlings - increased biomass» is not always true.

Soils phytotoxicity in the eastern industrial zone was moderate and ranged between $32.8 \%$ (which tends to soils with low phytotoxicity) and $49 \%$, which tends to unacceptable phytotoxicity. The average phytotoxicity in this area was $42.5 \%$.

The above material about the changes in soils phytotoxicity in the industrial areas of Stavropol should be correlated with soils phytotoxicity in the background areas, not affected by pollution. Since the city itself occupies the Stavropol upland, the «background» was the recreation areas of the city situated in the watersheds of the city. The average phytotoxicity of soils of the recreation area was $25.3 \%$, which corresponds to the level of low phytotoxicity. On the outskirts of the forest in locations of contact with residential areas, the phytotoxicity was 34.4$34.7 \%$. In the center of the forest, the lowest phytotoxicity of $16.8 \%$ was detected, which was taken as the reference.

Change in the phytotoxicity in functional areas was as follows: recreation area $(16.8 \%)<$ South-Western industrial area (30.2\%) < Eastern industrial area $(42.5 \%)<$ North-West industrial area (49.8\%).

This materials show that soil in the industrial areas are different in phytotoxicity, however, it is worth showing the changes in this parameter in comparison with the recreational area, in order to determine the environmental situation in the above areas.

In our case, the North-Western industrial area can be characterized as the area of ecological disaster, the Eastern industrial area - as the area of adverse environmental situation, and in the SouthWestern industrial area, the situation is relatively satisfactory, bordering with adverse (Table 3).

Soils phytotoxicity of residential areas of the city

High-rise residential areas in Stavropol the South-Western (I) and the North-Western ( $\mathrm{I}_{\mathrm{a}}$ ) ones are characterized by high intensity of traffic and are adjacent to the industrial areas of the city.

Studying soils of the south-western residential area for phytotoxicity showed that it varies in a wide range: between $28.0 \%$ and $52.1 \%$. Very high phytotoxicity was found in the residential areas located along the major intraregional highways (43.2 to $52.1 \%$ ).

In the North-Western residential area, soils are classified as medium-toxic, with toxicity ranging between 33.0 and $35.4 \%$. This zone is characterized by low impact of traffic, since traffic is redistributed from the major highway to secondary streets. Close to the forest areas, phytotoxicity is reduced. Therefore, forests serve as a kind of a barrier, which prevents spreading pollution from the highways.

The residential mixed zone (II) occupies the central part of the city. The area is dominated by traffic load, due to considerable traffic towards the South-Western and North-Western residential areas, as well as in the direction of the Eastern industrial area and roads to cities of Mikhaylovsk and Svetlograd. In addition, within this area, there are schools, institutions and agencies, the central bus station, and the railway station. Phytotoxicity of soils in this area varies from $26.5 \%$ (low phytotoxicity) to $40.0 \%$ (medium phytotoxicity); the indicator for the whole area was $37.9 \%$. There 
are areas with low phytotoxicity - the areas adjacent to the forest and located on the North side of the watershed and without roads and industrial enterprises in the infrastructure. High toxicity is observed in the area of the central avenue of the city. At its intersection with major streets that are the main city junctions, soil becomes highly toxic. Due to the fact that industrial enterprises are absent in this functional area, the main impact is predominantly from traffic.

Low-rise residential areas (III) occupy the slopes of valleys of the Tashla and Mamayka rivers. The Tashla district is bounded on one side by the North-Western residential area located on the plateau, and on the other side - by the watershed area (the central part of the city). The average toxicity is $38.2 \%$. Phytotoxicity increases in the area quite sharply: in the watershed, it is $24.8 \%$, and in the lower part of the transeluvial landscape, it is $37.3 \%$. This considerable increase in soil toxicity in a fairly short interval is caused not only by side drift from the watershed, but also by the landslide processes that are intensively developed on the slopes, and by repeated contamination of soils by groundwater flooding. According to the methodology of assessment criteria for the ecological situation of territories for revealing zones of adverse ecological situation and the areas of ecological disaster, despite local phytotoxicity increase in some districts of the city to unacceptable indicators, in high-rise residential areas of the South-Western (I) and the NorthWestern $\left(I_{a}\right)$ neighborhoods and the low-rise area (the area of Tashla) (III), the environmental situation may be characterized as satisfactory. In the mixed residential area (the center of the city), emergency environmental situation is observed, and the Mamayka district (low-rise area) (III ) may be attributed to the zone of ecological disaster (Table 4).

Based on the degree of the load on residential areas of the city, it should be assumed that the phytotoxic effect will occur in the following order: recreational area $<$ residential low-rise area $<$ residential areas with mixed buildings $<$ high-rise residential area. It is in this order that the motor traffic load increases; besides, the South Western (I) and the North-Western $\left(\mathrm{I}_{\mathrm{a}}\right)$ residential areas, and the lower part of the central residential area (II) experience additional stress from being in proximity to the industrial zones of the city.

However, as it can be seen from the figure, the situation is absolutely opposite: against the background of the recreational areas of the city, according to the degree of increasing the phytotoxic effect, the residential areas were distributed as follows: the residential high-rise areas $<$ residential mixed areas $<$ low-rise residential areas. This phenomenon may be explained from the point of view of the residential areas location in the natural landscape.

\section{Manifestation of the fluctuating asymmetry in the leaves of Betula pendula}

Studies have shown that the coefficient of fluctuating asymmetry (CFA) is distributed unevenly: the asymmetry coefficient by the quadrats ranged between 0.038 (1 point) and 0.06 (5 points). Thus, the ecological state in the area varies from relatively clean to highly unfavorable.

In the North-Western industrial area, the value of asymmetry in the sampling ranged between 0.04 (disturbed area) and 0.06 (extremely unfavorable). On the average for the area, the CFA was 0.045 . Almost the entire area may be classified as environmentally disturbed and strongly disturbed territory.

Since the entire industrial zone is crossed by the Kulakov Avenue, which belongs to the major feed lines of the regional center, the whole area is in fact located within the road landscape. The minimum value of the fluctuating asymmetry (0.04) was observed only at the location of contact with the recreation area (the forest adjacent to the Kulakov Avenue).

The average asymmetry indicator in the South-Western and the Eastern industrial areas was 0.049 , which also characterizes the territory as considerably disturbed, and ecologically closer to adverse.

On the average, in the South-Western residential area (I) the FCA amounted to 0.044, which characterizes the area as disturbed. The boundary value between conditionally good and disturbed areas is marked in new districts only. Considerably disturbed areas with the asymmetry coefficient of 0.045 were identified along the highways of the area and at their intersections. The average coefficient of fluctuating asymmetry in high-rise buildings blocks was 0.0436, which characterizes the area as disturbed. 
The average coefficient of fluctuating asymmetry in the North-Western $\left(\mathrm{I}_{0}\right)$ buildings block was 0.0436, which characterizes the area as disturbed.

In the area of mixed housing (II), where there are one-storey houses neighboring high-rise buildings, many offices and administrative buildings and high traffic load, the indicator of fluctuating asymmetry increased considerably, and averaged 0.048 , which is comparable with the industrial areas of the city. Very high values are observed along highways that cross the entire central part of the city. In the central part of the area, the values of asymmetry were often higher than the values in the industrial areas- 0.05 to 0.58 . Virtually the entire territory belongs to adverse one.

The indicators of fluctuating asymmetry in the residential (low-rise) area located on the slope of the southern exposure of the Tashla River (III) varied less considerably, as compared to the central residential area. The dispersion of this indicator was 0.041-0.054; and the average indicator for the area was 0.0475 , which corresponds to considerably disturbed areas. Considerable values of the FCA at the level of adverse environmental condition are observed along the central highway and increase down the slope (Figure 1). Similar data was obtained by E. A. Ostroverkhova (2011) in studying the agricultural landscapes of Stavropol.

In the residential (low-rise) area (III) located on the southern slope of the valley of the Mamayka River, the range of FCA indicators amounted to 0.042-0.051, the average value being 0.0465 .

Table 5 shows the characteristics of the environmental condition of the functional zones area of the city.

\section{Assessing the state of environment by the complex of traits in Pinus sylvestris}

As it was mentioned in the research methodology, the relationship between "pure atmospheric air - life span of needles" is actually determined by the value of index Q. By this criterion, in the studied territory, the areas with the lowest level of atmosphere pollution were identified in the forest areas of the city $\mathrm{Q}=8.5$ 9.6, in the park area $(\mathrm{Q}=8.6)$ and the city park, where $\mathrm{Q}$ is 8.0. The minimum values of the Pinus sylvestris needles life span indicator $(\mathrm{Q}=3.6-5.6)$ were observed in the industrial areas of the city and close to the major highways. In course of monitoring it was found that with increasing age, the number of needles is greatly reduced, in particular, the number of pines with needles of age IV is 2.3 times lower than that of pines with needles of age I.

The morphometric studies of Pinus sylvestris needles showed that increased anthropogenic load in the neighborhood of highways and industrial enterprises results in thickening (coefficient of variation - 15.5\%) and shortening (coefficient of variation $-3.62 \%$ ) of needles. In the same quadrats, the number of needles per shoots of $10 \mathrm{~cm}$ long in the previous year was $220-226$, and in the forest areas -197 . This is because in unfavorable conditions, the growth of Pinus sylvestris shoots slows down, which leads to denser arrangement of the needles (Fedorov, Nikolskaya, 2001).

With increasing anthropogenic load, the weight of 1,000 absolutely dry needles decreased to 10.6 - $11.2 \mathrm{~g}$, as compared to the reference samples (12 g). The coefficient of variation according to this feature amounted to $3.69 \%$, which indicates its weak variability.

Table 6 shows correlation analysis of the relationship between the studied morphometric indicators of pine needles.

The table data shows that there is a very strong correlation between these indicators in Pinus sylvestris. Existence of such relationships makes it possible to say that abnormal symptoms are absent, and pines in the city develop in accordance with their biological peculiarities.

In addition to the morphometric parameters of pine needles, an informative indication of the degree of pollution of the ecosystem is the nature of damage and drying).

The results showed that in all quadrats, the needles with the second class of damage (CoD 2) are present, which indicates a moderate anthropogenic impact. Besides, needles of the third class (CoD 3) that are most affected with spots were observed in the majority of quadrats, except for the quadrats in the forest and park areas.

According to the method used, four classes of drying are identified by the degree of needles drying. The results showed that the needles with the highest drying class (CDr 4) are 
found in the quadrats with high degree of environmental pollution due to vehicle emissions. Comparing the results of bioindication and biotesting

Today, biological studies are focused on finding the optimum criteria for assessing the quality of the environment. This is due to the fact that the species-bioindicators selected for whatever reasons may not be universal for all cases, as evidenced by the data above. For the purpose of comprehensive numerical evaluation of ecosystems degradation in the anthropogenically transformed areas under the anthropogenic load, the integrated factor of safety (ICP) in the urban ecosystems was used.

The integral coefficient of preservation of ecosystems ranges between 36.1 and 99.78\%. According to Stepanov A. M. (1991), in region of ICP between 100 and 80\% (regional background), the structural organization of the ecosystem is preserved, although all indicators are decreasing. The area of ICP between 80 and $20 \%$ is characterized by simplified structure of the ecosystem with increasing anthropogenic impact; the area of ICP below $20 \%$ is an anthropogenic desert (no such quadrats were detected in the territory of Stavropol).

Figure 2 shows the data describing ICP of the ecosystems in various functional areas of the city. One can see that even the forest areas within the city limits are already different from the regional background quadrats. In the rest of the landscapes of the city, simplification in the structure of phytocenosis is observed. In some industrial areas and in the residential area located on the slope of the river valley, preservation of the ecosystem is only slightly over $36 \%$.

Altogether, the ICP perfectly reflects the results of biomonitoring and biotesting; in this connection we can draw the conclusion that ICP provides the opportunity to express the condition of an ecosystem by a single number, comparison of which to the anthropogenic loads provides the sought "dose to effect" dependence at the level of the entire ecosystem.

At the moment, it is the method of compressing data, which in this form may be used by organizations involved in making managerial decisions at all stages: pre-planning, planning, predesign, design, and operation. Using ICP opens the prospect of practical implementation of environmental regulation, environmental assessment and environmental monitoring.

\section{CONCLUSION}

The above data and generalization thereof show that the methods of bioindication and biotesting may be used for assessing the ecosystems in urban areas. However, in the future it is necessary to perform comparative analysis of biomonitoring results, and heavy metals content in the same soil samples. This is especially true for the areas with unfavorable environmental conditions; e.g., with migration of contaminants from the surface and subsurface drain, or in case of intensive load from industrial enterprises or highways.

It is still not quite clear how heavy metals influence the manifestation of the fluctuating asymmetry in Betula pendula and the morphometric parameters of needles in Pinus sylvestris.

The evaluation scale for the integral coefficient of ecosystems preservation should be more detailed in gradation of preservation of ecosystem of $20-80 \%$, which requires additional research, including the use of various bioindicators, physical and chemical studies of soil, air and detailed assessment of anthropogenic load. For the purpose of normalizing the detected load on ecosystems, it is also necessary to have an accurate representation of the marginal, "critical" value of this load, which results in irreversible changes in specific ecosystems; it is also required for predicting future condition of ecological systems.

The authors express their gratitude to the staff of the Department of Ecology and Landscape Construction of the Stavropol State Agrarian University and to the students of the "Ecology and nature" specialty involved in organizing and performing the monitoring.

\section{REFERENCES}

1. Kapusta, P., \& Sobczyk, L., Effects of heavy metal pollution from mining and smelting on enchytraeid communities under different land management and soil conditions. The Science of the Total Environment, 2015; 536: 517-26.

2. Yoon, Y., Lee, W., \& An, Y., Phytotoxicity of 
arsenic compounds on crop plant seedlings. Research Article. Environmental Science and Pollution Research, 2015; 22(14): 11047-11056.

3. Tkachenko, Y.D., Pospelova, O.A., \& Stepanenko, E.E., Biotesting of soil contamination in industrial areas of Stavropol. Russian Journal of Earth Sciences, 2013; 1(13): 47-59.

4. Tkachenko, Y.D., Using methods of bioindication and biotesting in environmental monitoring (on the example of Stavropol). Bulletin of Stavropol AIC, 2012; 1(5): 107-111.

5. Ostroverkhova, E.A., Biotesting of soils in the agricultural areas of Stavropol. Proceedings of the II International Scientific-Practical Conference, Stavropol, 2011; 82-84.

6. Vorobyov, S.A., Accumulation and distribution of heavy metals and radionuclides in park ecosystems (Candidate's thesis, 2005; 135). Orel.

7. Mandra, Y.A., Plants as indicators of the ecological state of a health region environment (on the example of Kislovodsk (Candidate's thesis, 2010; 148). Stavropol.

8. Degtyareva, T.V., Geochemical features of the landscapes of Stavropol (Candidate's thesis, 2003; 194). Rostov-on-Don.

9. Alexeev, Y.V., Heavy metals in soils and in plants Leningrad: Agropromizdat., 1987; 115

10. The methodology of morpho-physiological assessment of winter wheat seedlings. Environmental monitoring of agricultural crops with the use of biological testing methods (recommendations). The State Scientific Institution "Research Institute of Agriculture”, Mikhailovsk, 2005; 33.

11. Zakharov, V.M., Clark, D.M., Biotest: Integral evaluation of ecosystems and individual species health. Moscow: The Moscow branch of the "Biotest” International Fund, 1993; 68.

12. Zakharov, V.M., Health of environment: a concept. Moscow: The Center of Ecological Policy of Russia, 2000; 30.

13. Konstantinov, E.L., Features of the FA of a lamina of drooping birch (Betula Pendula) as a kind of bioindicator (author's abstract from Candidate's thesis, Kaluga, 2001; 19.

14. Korosov, A.V., Special methods of biometrics. Petrozavodsk: PSU, 2007; 91-105.

15. Fedorova, A.I., \& Nikolskaya, A.N., Hands-on training in ecology and environmental protection: manual for students of universities. Moscow: Humanit. ed. center VLADOS, 2001; 288.

16. Denisova, S.I., Field practice in ecology: a Learning guide Minsk, 1999; 120.

17. Stepanov, A.M., Methodology of bioindication and background monitoring of terrestrial ecosystems. Ecotoxicology and nature protection. Moscow: Nauka., 1988; 28-108

18. Stepanov, A.M., Bioindication at the level of ecosystems. Bioindication and biomonit oring Moscow: Nauka, 1991; 59-64.

19. Teplaya, G.A., Heavy metals as a factor of environmental pollution (review of literature). The Astrakhan Bulletin of Ecological Education, 2013; 1(23): 182-192.

20. Shimanskaya, E.I., Buraeva, E.Y, \& Varduni, T.V., Ten-years of biomonitoring urbanized areas with the use of tree herbs. Advances of Modern Natural Science, 2014; 11-2: 102-103.

21. Esyakova, O.A., \& Stepen, R.A., Indication of atmosphere pollution in Krasnoyarsk by morphometric and chemical parameters of firneedles of Siberian spruce. Chemistry of Vegetable Raw Materials, 2008; 1: 143-148. 